\title{
The Faculty Construction of Independent College From the Perspective of Performance Management
}

\author{
Xin Ding ${ }^{*}$ \\ Yangzhou University Guangling College, Yangzhou, Jiangsu, China \\ ${ }^{*}$ Corresponding author

\begin{abstract}
According to the requirements of education departments for the construction of teachers, independent colleges have invested a lot of energy to promote the construction of teachers. However, there are still many problems, such as the difficulty of talent introduction, the unreasonable structure of teachers, the difficulty of in-service training and the imperfection of incentive mechanism. On the basis of analyzing those problems, it is suggested that independent colleges should set up the concept of performance management, build a performance management system integrating evaluation indicators, teacher training, assessment, job promotion, salary and post appointment, improve the working enthusiasm, and promote the connotation construction of faculty.
\end{abstract}

Keywords: Independent college, Faculty, Performance

\section{绩效管理视域下独立学院师资队伍建设 \\ 丁欣*}

扬州大学广陵学院, 江苏扬州, 中国

“通讯作者

\section{中文摘要}

根据教育等部门对师资队伍的建设要求, 各独立学院都投入大量精力推动师资队伍建设。但目前教师 队伍仍存在人才引进难、师资队伍结构不合理、教师在职培养落地难、管理激励机制不完善等问题。 在对问题进行分析的基础上，建议独立学院应树立绩效管理理念，构建集评价指标、教师培养、考核、 职务晋升、工资薪酬和岗位聘任为一体的绩效管理体系, 提高教师工作主动性, 推动独立学院师资队 伍内涵建设。

教师队伍是发展教育的重要资源, 是支撑新时代国家教育改革的关键力量。教育部、国家发展改 革委、财政部《关于引导部分地方普通本科高校向应用型转变的指导意见》（教发（2015）７号） [1] 中就已经指出要不断完善促进转型发展的政策体系, 推动院校设置、招生计划、拨款制度、学校治理 结构、学科专业设置、人才培养模式、师资队伍建设、招生考试制度等重点难点领域的改革。

《中共中央国务院关于全面深化新时代教师队伍建设改革的意见》［2］（2018 年 2 月 2 日）进一 步明确全面深化新时代教师队伍建设改革的目标和措施。2019 年 1 月发布的《国家职业教育改革实施 方案》 [3]中提及到 2022 年一大批普通本科高等学校向应用型转变。

教育等行政部门关于应用型高等院校师资队伍建设的政策要求，为应用型高等院校尤其是独立学 院 “双师型” 师资队伍建设提出了详尽要求、指明了独立学院转型发展的方向。如何在中国特色社会 主义新时代发展背景下, 以政策制度为导向, 扎实推动师资队伍内涵建设, 以适应独立学院未来发展 值得深思。

关键词: 独立学院; 师资队伍; 绩效 


\section{1. 独立学院师资队伍的现状}

\section{1. 人才引进难，师资流动性大}

在人事管理转变为岗位管理的今天, 人员身份的问 题逐步淡化, 但中国人传统认知中对 “编制” 仍较 “迷 信”, 独立学院没有编制成了人才引进中的软肋。薪酬 待遇与事业编制人员同工同酬, 显然也不足以吸引高层 次人才和具有 “双师” 素养的教师加入独立学院师资队 伍。

同时随着职称评审权的下放，给人才流动带来更多 的便利, 人才流动性与日俱增, 教师们不再一份工作干 一辈子, 哪里有更好的发展平台、发展机遇、发展待遇 就去哪里。

\section{2. 师资队伍结构不合理}

自有教师队伍大多由返聘的老教授、具有硕士及以 上学历学位的青年教师组成。从年龄结构看呈两极分化, 老的老小的小; 从职称结构看，具有初级和高级专业技 术职务的老师少, 中级专业技术职务的老师多, 整体呈 纺锥型分布。

\section{3. 教师在职培养落地难}

教师自身对于在职培训参与积极性不高, 培训课程 鱼龙混杂很难找到贴合实际需求的培训。一旦学院对此 所持的态度不明确，会直接影响教师的积极性。

\section{4. 管理机制、激励机制不完善，缺乏灵活 性}

独立学院人事管理长期依靠于举办高校, 很多做法 承袭了举办高校多年的经验和智慧, 但忽视独立学院和 举办高校之间的区别, 无法激发独立学院教师工作的主 动性。

\section{2. 独立学院师资队伍建设中问题的成因}

\section{1. 对师资队伍建设的重要性认识不足}

独立学院长期以来自有教职工主要从事学生管理 工作, 教学工作依靠举办高校, 自有专任教师队伍建设 相对薄弱。对自有师资队伍建设的重要性认识不足, 在 即将转型发展的今天，仍持依靠举办高校的态度，显然 不利于独立学院未来的转型发展; 或者依旧遵循举办高
校的人事管理思路，可能会产生曲寡和高、不接地气的 现象。

\section{2. 师资队伍建设缺乏整体规划}

对于教师发展有的院校不阻碍也不提供有利条件, 教师发展培养全靠自身能力; 有的院校虽然每年将师资 的培养纳入考核指标, 但具体实施多以完成教师建设任 务为目标, 鲜有从整体队伍建设出发, 谋划具体的建设 规划。尤其是纺锥型职称结构的师资队伍，如何分类培 养，因才培养，避免扎堆式或一窝蜂式的培养，亟需对 学院 (校) 师资队伍进行整体规划。

\section{3. 制度建设脱离实际，实务操作缺乏灵活 性}

有的学院照搬沿袭了举办高校的人事管理制度，看 似 “有效” 的建立健全独立学院人事管理制度，但同时 会忽视了独立学院的实际。独立学院机构设置更精简, 工作任务交叉更多，庞大系统的制度对于独立学院可能 就会走形成臃肿繁琐，反而不利于师资队伍的发展。

\section{3. 解决的方法和策略}

绩效管理主要是通过不间断沟通, 推动团队和个人 达成目标的行为。它将公司的战略、资源、业务和行动 有机的结合起来，构成一个完整的管理体系 [4]。师资 队伍是促进独立学院发展的关键, 建立行之有效的绩效 管理系统, 对加强独立学院师资队伍建设、推动学院 (校) 教育教学发展具有现实意义 [5-6]。

\section{1. 树立绩效管理理念，构建绩效管理体系}

学院的管理者首先要树立绩效管理理念, 人事部门 建立科学的绩效管理体系, 将绩效管理理念渗透到教师 教学、科研、个人发展方方面面。

\section{2. 建立健全以人为本的评价指标体系}

从岗位入手，在遵循岗位职责的基础上，结合教师 的类型, 有的老师重教学, 那么评价指标可以侧重教学 方面的绩效; 有的老师是科研型, 则应侧重科研方面的 绩效评价; 有的老师是教学科研并重型, 就要建立兼顾 教学和科研两方面的绩效评价体系; 还有的老师属于双 师双能型师资，除了在教学、科研和社会服务基础指标 上突显双师特色，还应对 “双师” 成果运用方面建立绩 效指标。与此同时, 还需和应用型高等学校人才培养方 案相结合，制定以人为本的评价指标体系。 


\section{3. 依据评价指标体系, 建立健全教师培养、 考核和专业技术职务评聘制度}

以健全科学以人为本的评价指标体系为基础, 建立 健全教师培养制度, 实施分类培养, 有的放矢, 针对教 师的不同类型构建不同的培养体系, 并将培养过程中的 绩效成果体现在培养考核中; 围绕评价指标体系, 构建 科学合理的考核制度, 对于双师型教师, 还需构建学校、 行业/企业、培训基地等多元参与的 “双师型” 教师评 价考核体系; 融合与师资建设相关的引进、培养、考核 等制度, 健全专业技术职务评聘体系, 将绩效指标继续 加以体现。

\section{4. 建立健全绩效工资制度}

在人才引进时, 可以对引进人才建立专业技术职务 评聘绿色通道, 建立与绩效匹配的薪酬制度; 其他老师 则在对工作绩效进行合理评估后，建立与绩效贡献挂钩 的工资制度，如此可以充分发挥薪酬待遇对教师的激励 作用。

\section{5. 建立健全体现绩效管理的岗位聘任制度}

通过多层次、全方位的考核体系, 将教师的分类管 理和分类评价相结合，年度评价和聘期考核相辅相成， 聘期考核结果与下一聘期聘用挂钩, 对上个聘期考核优 秀、合格的教师做出晋级、续聘的决定, 对聘期考核不 合格的人员, 低一级聘用甚至不再续聘; 年度评价与绩 效工资挂钩, 按岗聘用、以岗定酬, 根据岗位变化及时 调整兄现相应的工资待遇。就此形成有效的目标激励机 制, 使教师绩效考核成为教师不断奋发向上的推动力。

\section{4. 小结}

根据教育等部门对师资队伍的建设要求, 各独立学 院都投入大量精力推动师资队伍建设。但目前教师队伍 仍存在人才引进难、师资队伍结构不合理、教师在职培 养落地难、管理激励机制不完善等问题。建立行之有效 的绩效管理系统, 对加强独立学院师资队伍建设、推动 学院（校）发展具有现实意义。独立学院应树立绩效管 理理念，构建集评价指标、教师培养、考核、职务晋升、 工资薪酬和岗位聘任为一体的绩效管理体系, 提高工作 主动性, 推动学院师资队伍内涵建设。

\section{致谢}

本文为江苏省教育厅 2019 年度高校哲学社会科学 研究项目《新时代背景下独立学院师资队伍建设研究 ——以扬州大学广陵学院为例》(编号: 2019SJA2174) 的阶段性成果之一。

\section{REFERENCES}

[1] Ministry of education, national development and reform commission, ministry of finance

Guiding opinions on the transformation of some local universities into application-oriented universities

(http://www.moe.gov.cn/srcsite/A03/moe_1892/moe_63 0/201511/t20151113_218942.html).

[2] CPC central committee and state council Opinions on comprehensively deepening the reform of the construction of teachers in the new era

(http://edu.cnr.cn/list/20180202/t20180202_524121490.s html).

[3] The State Council The circular on the issuance of the implementation programme of the national vocational education reform

(http://www.gov.cn/zhengce/content/2019-02/13/content _5365341.html).

[4] Miaohong Huang, ShiZhen Zheng. Study on the performance management of teachers in private vocational colleges[J]. Human resource managemen, 2016(09):116-118.

[5] Xiaolu Lin. Research on the performance management of teachers in higher vocational colleges based on psychological contract theory[J]. Education and careers, 2017(06):63-66.

[6] Shaohua Zhang. Innovation of teacher performance management model in applied colleges and universities based on organizational communication theory [J]. Education and careers, 2018(12): 70-73. 